\title{
Evaluation of the metabolism of glycosaminoglycans in patients with interstitial cystis
}

Marcos Lucon, João Roberto Martins, Katia Ramos Moreira Leite, Roberto Soler, Helena B. Nader, Miguel Srougi, Homero Bruschini

Division of Urology (ML, KRML, MS, HB), University of Sao Paulo Medical School; Division of Urology (RS) and Division of Molecular Biology (JRM, HBN), Federal University of Sao Paulo, Sao Paulo, Brazil

\section{ABSTRACT}

Introduction: Painful bladder syndrome/interstitial cystitis (PBS/IC) pathogenesis is not fully known, but evidence shows that glycosaminoglycans (GAG) of bladder urothelium can participate in its genesis. The loss of these compounds facilitates the contact of urine compounds with deeper portions of bladder wall triggering an inflammatory process. We investigated GAG in urine and tissue of PBS/IC and pure stress urinary incontinence (SUI) patients to better understand its metabolism.

Materials and Methods: Tissue and urine of 11 patients with PBS/IC according to NIDDK criteria were compared to 11 SUI patients. Tissue samples were analyzed by histological, immunohistochemistry and immunofluorescence methods. Statistical analysis were performed using t Student test and Anova, considering significant when $\mathrm{p}<0.05$.

Results: PBS/IC patients had lower concentration of GAG in urine when compared to SUI (respectively $0.45 \pm 0.11 \times 0.62 \pm 0.13 \mathrm{mg} / \mathrm{mg}$ creatinine, $\mathrm{p}<0.05$ ). However, there was no reduction of the content of GAG in the urothelium of both groups. Immunofluorescence showed that PBS/IC patients had a stronger staining of TGF-beta, decorin (a proteoglycan of chondroitin/dermatan sulfate), fibronectin and hyaluronic acid.

Conclusion: the results suggest that GAG may be related to the ongoing process of inflammation and remodeling of the dysfunctional urothelium that is present in the PBS/IC.

\section{ARTICLE INFO}

Key words:

Cystitis, Interstitial; Glycosamino-

glycans; Hyaluronic Acid

Int Braz J Urol. 2014; 40: 72-9

Submitted for publication:

November 07, 2012

Accepted after revision:

July 24, 2013

\section{INTRODUCTION}

Painful bladder syndrome/interstitial cystitis (PBS/IC) is a chronic syndrome that affects the lower urinary tract and which diagnosis is based on urinary symptoms and chronic pelvic pain or discomfort related to the bladder (1). Its aetiopathology is not fully known, but it is believed that the glycosaminoglycans (GAGs) and proteoglycans (PGs) that line the bladder urothelium can actively participate in its genesis. They potentially help to prevent infections, stone formation, and tissue damage related to radiation carcinogenesis and interstitial cystitis. The biological activity of this layer is generated by the anionic charge of the polysaccharides forming the GAG. They are highly hydrophilic and are adhered to the surface of transitional cell bladder. That avidity for water molecules creates a barrier that prevents migration of solutes from urine through epithelium $(2,3)$. Their capacity to prevent part of the urinary solutes to reach the interstitium has been demonstrated in studies that found increased urea and potassium absorption by bladder wall when the GAG layer is damaged. 
Urine and tissue levels of GAG have been studied in PBS/IC and in animal models but their results are not uniform (2,4-18). Such variation suggests that there is no complete understanding of how and why GAG is produced and degraded in PBS/IC, if GAG expression is the cause or the reaction for PBS/IC. Or both cause and reaction. The mechanisms of changes in GAG levels that can occur during the course of the syndrome are not precisely described although some have correlated disease severity to symptoms (4). We investigated GAG behavior in an attempt to understand its metabolism and the chemical reactions related to the expression of those polisaccharides in tissue and urine.

\section{MATERIAL AND METHODS}

Female patients with confirmed diagnosis of PBS/IC $(n=11)$ according to the NIDDK criteria except for glomerulations were subjected to clinical questionnaire assessing age, date of onset of symptoms, coexisting diseases, severity of symptoms, type of previous treatment and quality of life index. They underwent cystoscopy for urine collection followed by bladder biopsy. In the same procedure bladder hydrodistention was done for 3 minutes and $80 \mathrm{CmH}_{2} 0$ pressure (19). Mean age was 48 (26-73) years.

The control group $(\mathrm{n}=11)$ was composed of female patients with pure stress urinary incontinence (SUI) that also underwent bladder biopsies at the time of cystoscopy as a part of surgical correction of the underlying disease. Again a new sample of urine was collected at the time of the surgery and bladder biopsy was taken. These patients also had previous negative urinary culture and an urodynamic study realized 3 months earlier in order to exclude eventual non-inhibited detrusor contraction. This group was chosen as the control group because a bladder cold biopsy would add little risk to them, as cystoscopy was mandatory in their surgical treatment. Mean age was 64 (50-79) years.

The study was approved by the ethics committees and a consent form was signed by participants.

The tissue samples were referred to the following analysis: histological, immunohisto- chemistry and immunofluorescence, and RNA expression by real time PCR.

\section{Extraction of Tissue Glycosaminoglycans}

Tissue samples from six patients with interstitial cystitis and 7 controls (SUI) were processed and analyzed biochemically for the content of sulfated GAG, as previously described (20-22). Briefly, the bladder tissue samples were shredded into 10 volumes of acetone to remove water and lipids. The ketonic powder obtained was then subjected to proteolysis with the enzyme maxatase $4 \mathrm{mg} / \mathrm{ml}$ (Biocon Industrial of Brazil, Rio de Janeiro, Brazil) in Tris-HCL50mM, NaCl1M, pH 8.0, "overnight". Peptides and nucleic acids were precipitated with trichloroacetic acid 90\%, and the GAG precipitated from the supernatant by addition of methanol. After incubation at $-20^{\circ} \mathrm{C}, 18$ hours, the precipitate (containing GAGs) was dried and resuspended in distilled water $(1 \mathrm{~mL}$ for each $\mathrm{mg}$ of dry tissue). The identification of the different GAG obtained by the procedure above was done by agarose gel electrophoresis in 1.3 diaminopropane acetate buffer $0.05 \mathrm{M}, \mathrm{pH} 9.0$ (PDA). Five mL of each sample as well as $5 \mu \mathrm{L}$ of a mixture of standard GAG (containing $1 \mathrm{mg} / \mathrm{mL}$ of chondroitin sulfate, dermatan sulfate and heparan sulfate, all of Seikagaku Kogyo Co., Tokyo, Japan) were applied to the same gel and subjected to electrophoresis, $100 \mathrm{~V}$, one hour. The starting point of electrophoresis corresponds to the negative pole as a function of the negative charge of GAG they migrate toward the positive pole. Thus, this system can discriminate, in order of decreasing electrophoretic mobility, three major GAG: chondroitin sulfate (CS), the dermatan sulfate (DS) and heparan sulfate (HS), respectively. Finally, the GAG were precipitated in the gel by the addition of cetyltrimethyl ammonium bromide (CETAVLON, Sigma-Aldrich, St. Louis, MO) $0.1 \%$ for a minimum of two hours at room temperature. After drying under heat and ventilation, the gel was stained with toluidine blue solution $0.1 \%$ acetic acid 1\% and 50\% ethanol for about 15 minutes. The excess dye was removed with a solution of 1\% acetic acid in 50\% ethanol. Quantification of GAG present in different samples was performed by optical densitometry equipment in A595nm QuickScan (Helena Laboratories, Seiko, 
Japan) and compared to the existing content of the standard mix. The values were expressed as $\mathrm{mg} / \mathrm{mg}$ of dry powder.

Extraction and quantification of sulfated GAGs and hyaluronic acid in the urine

For analysis of sulfated GAG, $8 \mathrm{~mL}$ of each urine were concentrated and washed twice with distilled water $(8 \mathrm{~mL})$ in tubes of Amicon Ultra concentration 3kDa (Millipore Corporation, Carrigtwohill, Ireland) to a final volume of $20 \mathrm{~mL}$. Five $\mathrm{mL}$ of the solution were subjected to electrophoresis as described above, and the GAG present in the sample quantified by comparison with a standard mix of GAG (containing $1 \mathrm{mg} / \mathrm{mL}$ of chondroitin sulfate, dermatan sulfate and heparan sulfate, all of Seikagaku Kogyo Co, Tokyo, Japan). The content of GAG present in different samples was expressed as $\mathrm{mg} / \mathrm{mg}$ creatinine. The analysis of the HA method was performed as previously described $(23,24)$. Briefly, $100 \mathrm{~mL} /$ well of each urine (diluted 1:2 in assay buffer Tris-HClo, $05 \mathrm{M}, \mathrm{pH} 7.75+1 \% \mathrm{BSA}$ ) and the same amount of a standard curve $(0-1000 \mathrm{ng} / \mathrm{mL})$ from human umbilical cord HA (Sigma-Aldrich, St. Louis, MO) were applied in triplicate in ELISA plates (Perkin-Elmer Life Sciences-WallacOy, Turku, Finland) pre coated with an HA-binding protein extracted from bovine nasal cartilage (21). After incubation at $4^{\circ} \mathrm{C}, 12$ hours, the plates were washed six times with wash buffer (Tris-HCl0, 05M, pH 7.75) followed by the addition of HA binding protein labeled with biotin $(1 \mathrm{mg} / \mathrm{mL})$ diluted in assay buffer. The plates were then shaken at room temperature for 2 hours and washed 12 times with the wash buffer to remove protein not complexed to the biotinylated HA retained on board. Finally, the presence of biotin on the plate was determined by adding $100 \mathrm{~mL} /$ well of streptavidin labeled with europium (Perkin-Elmer Life Sciences-Wallac0y, Turku, Finland) diluted 1:10,000 in assay buffer, 30 minutes. To measure the fluorescence emitted by europium, $200 \mathrm{~mL}$ of a solution Enhancement (Perkin-Elmer Life Sciences-WallacOy, Turku, Finland) were added to each well and read on equipment Victor 2 (Perkin-Elmer Life Sciences-WallacOy, Turku, Finland). HA values were expressed in $\mathrm{ng} / \mathrm{mg}$ of creatinine.

\section{Immunofluorescence of tissue}

The tissue samples of patients with PBS/IC $(n=6)$ and control patients with SUI $(n=4)$ were washed in PBS and immediately fixed in 4\% paraformaldehyde solution for 2 hours at room temperature. Then the fragments were embedded in freezing medium for fluorescence Tissue freezing medium Tissue Tek (SakuraFinetek USA, Inc., Torrance, CA, USA) and frozen on dry ice and isopentane, and kept in a freezer at $-70^{\circ} \mathrm{C}$, which were placed on silanized slides. The following cuts were made in a cryostat (Leica, Wetzlar, Germany) with a thickness of about $5 \mathrm{~mm}$. For immunofluorescence reactions the sections were washed five times with PBS and one time with PBS containing $0.1 \mathrm{M}$ glycine At this stage three antibody combinations were made in separate slides for analysis: 1) anti-CD44 (Santa Cruz Bioechnology Inc., CA, USA) vs. probe of biotinylated HA binding protein (prepared in our laboratory according to Martins et al., 2003); 2) antidecorim (Seikagaku, Japan) vs. anti-TGF- $\beta$ (Santa Cruz Bioechnology Inc., CA, USA); 3) anti-SINDEC (Bioechnology Inc. Santa Cruz, CA, USA) vs. anti-fibronectin (Bioechnology Inc. Santa Cruz, CA, USA). The slides were incubated with the antibodies mentioned above and also with the acid-binding protein, for 2 hours at room temperature. At the end of incubation, the slides were washed 3 times in PBS, and now incubated with secondary antibody or streptavidin conjugated with fluorescent marker Alexa FluorTM 488 or 594 or 546 or 630 or 430 (the number corresponds to the wavelength of excitation of the fluorophore conjugated) diluted 1:300 in PBS. After 30 min. of incubation, the slides were washed five times in PBS and nuclei were marked with DAPI (4'6-diamidino-2-phenylindole, dihidrocloride - marking in blue) 1:10,000 in PBS containing $0.01 \%$ saponin (detergent that permeates the cell membrane) for $30 \mathrm{~min}$. Next, the slides were washed five times in PBS, washed again in ultrapure water and finally mounted with coverslips in histological Fluormont G (Electron Microscopy Sciences, Hatfield, PA, USA). The slides were observed and analyzed with a fluorescence microscope (Nikon Eclipse, TE300 and TE800, Tokyo, Japan) and confocal microscope (LSM500 meta - Carl Zeiss, Germany). The controls for the immunostaining experiments were performed omitting the primary antibody. 
RESULTS

Table-1 summarizes the demographics of the patients.

Although the average concentration of GAG in tissue was higher in patients with PBS/ IC $(3.3 \mathrm{mg} / \mathrm{mg}$ dry tissue, range: 0.58 to 7.08 ) than in the control group $(2.7 \mathrm{mg} / \mathrm{mg}$ dry tissue, range: 0.15 to 5.3 ), this difference was not statisti- cally significant ( $p=0.62$ ) (Figure-1). Chondroitin sulfate (CS) and dermatan sulfate (DS) were compared to heparin sulfate (HS): CS + DS were the main component in the urothelium (mean CS + DS: PBS/IC 74.3\%, control 78\%; mean HS: PBS/IC 25.7\%; control 22\%).

In urine we found a statistically significant decrease $(p<0.05)$ of GAG in the PBS/IC group $(0.45 \pm 0.11 \mathrm{mg} / \mathrm{mg}$ creatinine) compared to

Table 1 - Demographics of IC/PBS and SUI patients.

\begin{tabular}{|c|c|c|c|}
\hline Pacient & Age (Year) & Symptoms & Urinary culture at surgery \\
\hline IC/PBS 1 & 27 & Vesical pain, nicturia & Negative \\
\hline IC/PBS 2 & 40 & Vesical pain, nicturia & Negative \\
\hline IC/PBS 3 & 53 & Supra pubic pain, nicturia & Negative \\
\hline IC/PBS $4^{*}$ & 64 & Nicturia & E.coli \\
\hline IC/PBS 5 & 65 & Vesical pain, nicturia, anal pain, dispareunia & Negative \\
\hline IC/PBS 6 & 73 & Vesical pain, nicturia, frequency & Negative \\
\hline IC/PBS 7 & 43 & Vesical pain, nicturia, dispareunia & Negative \\
\hline IC/PBS 8 & 27 & Vesical pain, nicturia & Negative \\
\hline IC/PBS 9 & 57 & Supra pubic pain, nicturia, dispareunia, frequency & Negative \\
\hline IC/PBS 10 & 26 & Supra pubic pain, nicturia, dispareunia, frequency & Negative \\
\hline IC/PBS 11 & 48 & Supra pubic pain, nicturia, dispareunia, frequency & Negative \\
\hline SUI 1 & 68 & Stress urinary incontinence & Negative \\
\hline SUI 2 & 53 & Stress urinary incontinence & Negative \\
\hline SUI 3 & 71 & Stress urinary incontinence & Negative \\
\hline SUI 4 & 64 & Stress urinary incontinence & Negative \\
\hline SUI 5 & 61 & Stress urinary incontinence & Negative \\
\hline SUI 6 & 59 & Stress urinary incontinence & Negative \\
\hline SUI 7 & 64 & Stress urinary incontinence & Negative \\
\hline SUI 8 & 50 & Stress urinary incontinence & Negative \\
\hline SUI 9 & 79 & Stress urinary incontinence & Negative \\
\hline SUI 10 & 66 & Stress urinary incontinence & Negative \\
\hline SUI 11 & 54 & Stress urinary incontinence & Negative \\
\hline
\end{tabular}

* This patient was excluded because of UTI. 
the control group $(0.62 \pm 0.13 \mathrm{mg} / \mathrm{mg}$ creatinine $)$ (Figure-2). The percentage of GAG found in the urine of PBS/IC and controls was similar.

Although the average concentration of HA was lower in the PBS/IC group $(1.71 \pm 2.06 \mathrm{ng} / \mathrm{mg}$ creatinine) compared to the control group (2.46 $\pm 2.07 \mathrm{ng} / \mathrm{mg}$ creatinine), this difference was not significant $(\mathrm{p}=0.48)$.

The immunofluorescence study revealed an intense labeling for HA without a corresponding increase in the expression of its receptor, CD44 (Figure-3). The expression of TGF- $\beta$ and decorim was marked with greater intensity in two

Figure 1 - Urothelium concentration of sulfated GAG of IC/ BS and control (SUI) patients. Vertical bars represent the standard deviations. Statistically significant deviation was not found between groups $(p=0.62)$.

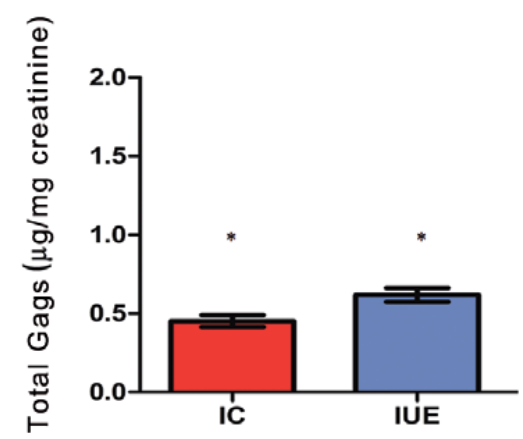

Figure 2 - Urinary concentration of sulfated GAG of IC/ PBS and control (SUI) patients. Vertical bars represent the standard deviations. Statistically significant difference was found between groups $(p<0.05)$.

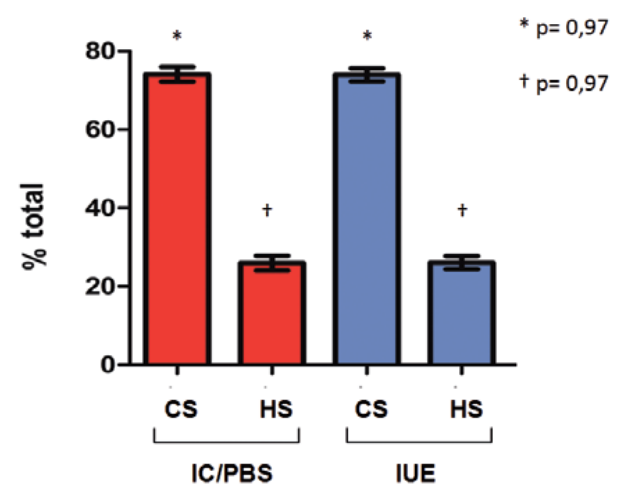

Figure 3 - Immunoflurorescence of hyaluronic acid (HA) and its receptor (CD44) in the bladder urothelium. The tissue of SIU patients (CTR) and IC/PBS patients (PAT) were labeled with anti-HA receptor (green) and a protein biotinylated HA binding (red). The nuclei were stained with DAPI (blue). The overlap of the markings appears in the right pane (merged). Scale bar: $50 \mu \mathrm{m}$.

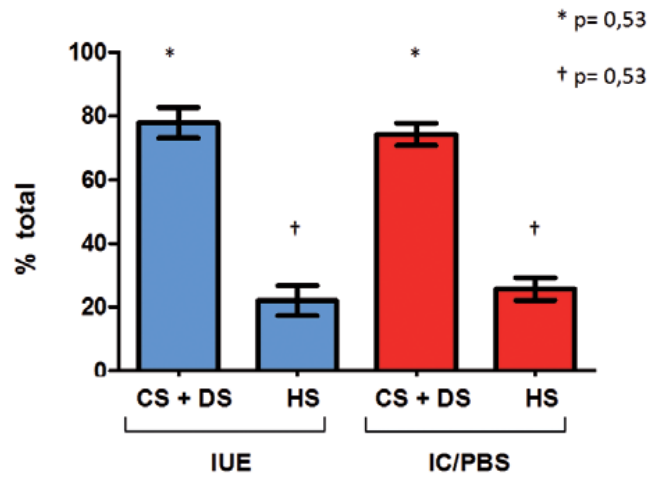

patients compared to controls. There was also an intense labeling for fibronectin in patients compared to controls. Syndecan-4 had a significant decrease in expression.

\section{DISCUSSION}

In the present study we were able to show that urinary levels of GAG are lower in PBS/IC patients when compared to controls but the relative proportion of each GAG is the same in both groups. On the other hand, tissue concentration of GAG was similar. HA in urine was similar in both groups but in immunofluorescence HA labeling was more intense in PBS/IC patients. The same happened for fibronectin, decorin and TGF- $\beta$.

Urinary GAG content in PBS/IC patients has been shown to be decreased $(25,26)$, similar $(27,28)$ and increased $(4,13,18)$. Our results showed a significant decrease in urinary excretion of sulfated GAG of patients with PBS/IC compared to the controls. Moreover, unlike previous studies, the technique employed in this study showed that the reduction in urinary GAG excretion in patients with PBS/IC occurred uniformly, with no predilection for any urinary GAG. Our study was not managed to analyze urinary GAG and the activity of the disease, such as degree of symptoms, glomerulation and histologic findings since they are not 
reliable isolated markers today (29). As for the HA, although the average urinary concentration was lower in the PBS/IC group but there was no significant difference when compared to control. Distinct methods of extraction could explain such variation. But it is possible that PBS/IC level of activity may influence urinary GAG level. As previously stated, correlation between urinary GAG level and symptoms has already been described $(4,13,18)$. We were not able to make such correlation.

However, urinary GAG level does not correlate to tissue GAG level. GAG expression in tissue has already been studied and no change in the content of GAG in the urothelium of patients with PBS/IC was described (8). The present study did not found statistically significant difference in the concentration of sulfated GAG in the urothelium of PBS/IC patients compared to controls. Hurst and Zebrowski (14) found the HS as the predominant GAG in the urothelium of patients with PBS/IC (55\% of total GAG) but in our study the major GAG present in those urothelium was a combination of CS + DS which accounted for about $80 \%$ of the total. That proportion was not different from that of the controls meaning they had a decrease of total GAG in tissue but not a predilection for any GAG. Different methods of extraction and analysis of the different GAG could justify such differences. Moreover, the small size of the fragments availabe for the study may have hindered the analysis and the interpretation of these data.

Growth factors may be also increased in patients with PBS/IC (30). We have demonstrated by immunofluorescence increased expression of TGF- $\beta$. Simultaneously the expression of decorin was increased, a proteoglycan composed of CS and DS chains involved in the regulation of various cellular functions such as proliferation, adhesion and migration, which is able to mediate the binding of TGF- $\beta$ with its membrane receptor (31). As the action of TGF- $\beta$ depends on decorin, it makes sense that decorin is increased in a scenario of increased TGF- $\beta$. We also noticed an intense labeling of fibronectin in tissues of PBS/ IC, especially in the deeper layers of tissue. Fibronectin is a glycoprotein with important role of scaffold in the extracellular matrix, regulating the cellular architecture and matrix components. Those higher expressions may represent modifications in the extracellular in an attempt to recovery urothelial damage. But one can not assure they are specific to PBS/IC. Variations are described in literature and this topic also remains controversial $(9,15,16)$.

Syndecan is a transmembrane receptor that mediates cell adhesion to fibronectin, playing a key role in healing. Its lower expression was consistent with a previous study from our group that observed in animal models loss of expression of HS and syndecan on the surface of the urothelium of rats after induction of inflammation with DMSO (9). As shown in the study, it may be results from desquamation of the dysfunctional urothelium.

Another important step in this study was the evaluation of the expression of HA and its receptor $\mathrm{CD} 44$ in the urothelium by immunostaining. Hyaluronic acid is a key component of the extracellular matrix due to its viscoelastic properties and its hygroscopic capacity, promoting hydration and turgidity. The HA forms a base to which other proteoglycans can bind (32). It was remarkable that $\mathrm{AH}$ showed intense labeling in the urothelium of PBS/IC compared to controls, while CD44 did not labeled significantly different. That could represent a paradox at a glance. The CD44 is the major membrane receptor for HA and is responsible, among other things, by its binding to and internalization into cells where this element is digested by lysosomal hyaluronidase and the digestion products are reused for new synthesis (33). The combination of intense marking HA without a corresponding increase in the marking of its receptor may indicate a change of its turnover in the urothelium of PBS/IC ending up this compound to be "stored" in the interstitial. That pattern may represent a response to inflammation. In studies of mice lacking the CD44 receptor (knock-out) accumulation of hyaluronic acid is seen during bleomycin-induced lung inflammatory process. The result is excessive and uncontrolled severity of the inflammatory process leading to death of the animal (34).

Although we found a heterogeneous pattern of immunofluorescence for all patients with 
PBS/IC, our findings are in agreement with other researchers, that analyzed biomarkers by immunohistochemistry in the urothelium of patients with cystitis and found distinct patterns of marking, sometimes with predominance of either one of a set of matrix components, but all the profiles different from those found in normal urothelium $(15,16)$. Whereas the inflammatory involvement of the urothelium does not occur uniformly, our current results and also those of Hauser et al. (16) suggest different profiles of involvement and expression of various inflammatory components of the extracellular matrix and depending on the different stages of inflammation and/or remodeling that each segment of the bladder is subject. That is why a pattern of GAG expression has not been achieved. Because those differences, one may speculate that they are not PBS/IC specific inflammatory process but rather a non-specific reaction to any aggression. In attempts to recovery, modeling of the extracellular matrix takes place in a dysfunctional urothelium. As the process is going on, distinct expressions may be identified and help to understand the phase of the disease.

The main limitation of this study is the small number of patients. Control patients were those with urinary incontinence subjected to surgical correction because bladder biopsy would add little risk to them. Even in those patients finding a volunteer was a challenge that would be more difficult when looking for healthy controls. The same limitation in the number of PBS/IC patients was found because the necessity of normalizing their selection for research restricts in up to $60 \%$ of those with clinically PBS/IC (35). There may also have had some bias in patient selection because our hospital is a tertiary referral for IC/ PBS. Another important issue was the small size of bladder biopsies. They were used for all the analyses and could not be taken in big bites because PBS/IC bladders have typically a high degree of inflammation and were done in the same procedure of hydrodistention.

\section{CONCLUSIONS}

The alterations in GAG may be related to an ongoing process of inflammation and tissue re- modeling in a dysfunctional urothelum, reflecting the pathophysiology of the disease.

\section{ACKNOWLEDGEMENTS}

\section{Financial support - FAPESP}

Juliana L. Dreyfuss, Elsa Y. Kobayashi, Yvette M. Coulson-Thomaz, Valquíria P. Medeiros, Aline Mendes and Marcelo Hisano

Division of Molecular Biology (JLD, EYK, YMCT, VPM, AM), Federal University of Sao Paulo and Division of Urology (MH),, University of Sao Paulo Medical School, Sao Paulo, SP

\section{CONFLICT OF INTEREST}

None declared.

\section{REFERENCES}

1. Hanno PM, Burks DA, Clemens JQ, Dmochowski RR, Erickson D, Fitzgerald MP, et al.: AUA guideline for the diagnosis and treatment of interstitial cystitis/bladder pain syndrome. J Urol. 2011; 185: 2162-70.

2. Lilly JD, Parsons CL: Bladder surface glycosaminoglycans is a human epithelial permeability barrier. Surg Gynecol Obstet. 1990; 171: 493-6.

3. Parsons CL: The role of the urinary epithelium in the pathogenesis of interstitial cystitis/prostatitis/urethritis. Urology. 2007; 69(4 Suppl): 9-16.

4. Lokeshwar VB, Selzer MG, Unwala DJ, Estrella V, Gomez MF, Golshani R, Kester RR, Klumpp DJ, Gousse AE: Uronate peaks and urinary hyaluronic acid levels correlate with interstitial cystitis severity. J Urol. 2006; 176: 1001-7.

5. Parsons CL, Greenspan C, Mulholland SG: The primary antibacterial defense mechanism of the bladder. Invest Urol. 1975; 13: $72-8$.

6. Parsons CL, Greenspan C, Moore SW, Mulholland SG: Role of surface mucin in primary antibacterial defense of bladder. Urology. 1977; 9: 48-52.

7. Parsons CL, Danielson B, Feldstrom B: Inhibition of sodium urate crystal adherence to bladder surface by polysaccharide. J Urol. 1985; 134: 614-6.

8. Nickel JC, Emerson L, Cornish J: The bladder mucus (glycosaminoglycan) layer in interstitial cystitis. J Urol. 1993; 149: 716-8. 
9. Soler R, Bruschini H, Truzzi JC, Martins JR, Camara NO, Alves MT, et al.: Urinary glycosaminoglycans excretion and the effect of dimethyl sulfoxide in an experimental model of non-bacterial cystitis. Int Braz J Urol. 2008; 34: 503-11; discussion 511.

10. Soler R, Bruschini H, Truzzi J.C, Alves M.T, Martins J.R, Dreyfuss $\mathrm{J}$, et al.: Role of urinary and urothelial glycosaminoglycans concentrations and DMSO local interaction in an experimental model of non-bacterial cystitis. Eur Urol. 2007; 2 (Suppl 6): 102.

11. Nickel JC, Downey J, Morales A, Emerson L, Clark J: Relative efficacy of various exogenous glycosaminoglycans in providing a bladder surface permeability barrier. J Urol. 1998; 160: 612-4.

12. Moldwin RM, Sant GR: Interstitial cystitis: a pathophysiology and treatment update. Clin Obstet Gynecol. 2002; 45: 259-72.

13. Lokeshwar VB, Selzer MG, Cerwinka WH, Gomez MF, Kester $R R$, Bejany DE, Gousse AE: Urinary uronate and sulfated glycosaminoglycan levels: markers for interstitial cystitis severity. J Urol. 2005; 174: 344-9.

14. Hurst RE: Structure, function, and pathology of proteoglycans and glycosaminoglycans in the urinary tract. World $\mathrm{J}$ Urol. 1994 12: 3-10.

15. Hurst RE, Roy JB, Min KW, Veltri RW, Marley G, Patton K, et al.: A deficit of chondroitin sulfate proteoglycans on the bladder uroepithelium in interstitial cystitis. Urology. 1996; 48: 817-21.

16. Hauser PJ, Dozmorov MG, Bane BL, Slobodov G, Culkin DJ, Hurst RE: Abnormal expression of differentiation related proteins and proteoglycan core proteins in the urothelium of patients with interstitial cystitis. J Urol. 2008; 179: 764-9.

17. Hanno P: Potassium sensitivity test for painful bladder syndrome/interstitial cystitis: con. J Urol. 2009; 182: 431-2, 434.

18. Akçay T, Konukoğlu D: Glycosaminoglycans excretion in interstitial cystitis. Int Urol Nephrol. 1999; 31: 431-5.

19. Forrest JB, Moldwin R: Diagnostic options for early identification and management of interstitial cystitis/painful bladder syndrome. Int J Clin Pract. 2008; 62: 1926-34.

20. Dietrich CP, Dietrich SM: Electrophoretic behaviour of acidic mucopolysaccharides in diamine buffers. Anal Biochem. 1976; 70: 645-7.

21. Martins JR, Gadelha ME, Fonseca SM, Sampaio LO, De L Pontes PA, Dietrich CP, et al.: Patients with head and neck tumors excrete a chondroitin sulfate with a low degree of sulfation: a new tool for diagnosis and follow-up of cancer therapy. Otolaryngol Head Neck Surg. 2000; 122: 15-8.

22. Perosa SR, Porcionatto MA, Cukiert A, Martins JR, Passeroti CC, Amado D, et al.: Glycosaminoglycan levels and proteoglycan expression are altered in the hippocampus of patients with mesial temporal lobe epilepsy. Brain Res Bull. 2002; 58: 509-16.
23. Martins JR, Passerotti CC, Maciel RM, Sampaio LO, Dietrich $\mathrm{CP}$, Nader HB: Practical determination of hyaluronan by a new noncompetitive fluorescence-based assay on serum of normal and cirrhotic patients. Anal Biochem. 2003; 319: 65-72.

24. Martins JR, Furlanetto RP, Oliveira LM, Mendes A, Passerotti CC, Chiamolera MI, et al.: Comparison of practical methods for urinary glycosaminoglycans and serum hyaluronan with clinical activity scores inpatients with Graves' ophthalmopathy. Clin Endocrinol (Oxf). 2004; 60: 726-33.

25. Parsons CL, Hurst RE: Decreased urinary uronic acid levels in individuals with interstitial cystitis. J Urol. 1990; 143: 690-3.

26. Hurst RE, Parsons CL, Roy JB, Young JL: Urinary glycosaminoglycan excretion as a laboratory marker in the diagnosis of interstitial cystitis. J Urol. 1993; 149: 31-5.

27. Erickson DR, Ordille S, Martin A, Bhavanandan VP: Urinary chondroitin sulfates, heparan sulfate and total sulfated glycosaminoglycans in interstitial cystitis. J Urol. 1997; 157: 61-4.

28. Erickson DR, Xie SX, Bhavanandan VP, Wheeler MA, Hurst RE, Demers LM, et al.: A comparison of multiple urine markers for interstitial cystitis. J Urol. 2002; 167: 2461-9.

29. Hanno P, Lin A, Nordling J, Nyberg L, van Ophoven A, Ueda T, et al:: Bladder Pain Syndrome Committee of the International Consultation on Incontinence. Neurourol Urodyn. 2010; 29: 191-8.

30. Schwalenberg T, Stolzenburg JU, Ho TP, Mallock T, Hartenstein $\mathrm{S}$, Alexander $\mathrm{H}$, et al.: Enhanced urothelial expression of human chorionic gonadotropin beta (hCG $\beta$ ) in bladder pain syndrome/interstitial cystitis (BPS/IC). World J Urol. 2012; 30: $411-7$.

31. Shi Y, Massagué J: Mechanisms of TGF-beta signaling from cell membrane to the nucleus. Cell. 2003; 113: 685-700.

32. Nusgens BV: [Hyaluronic acid and extracellular matrix: a primitive molecule?]. Ann Dermatol Venereol. 2010; 137: S3-8.

33. Knudson W, Chow G, Knudson CB: CD44-mediated uptake and degradation of hyaluronan. Matrix Biol. 2002; 21: 15-23.

34. Krasiński R, Tchórzewski H: Hyaluronan-mediated regulation of inflammation. Postepy Hig Med Dosw (Online). 2007; 61: 683-9.

35. Hanno PM, Landis JR, Matthews-Cook Y, Kusek J, Nyberg $L$ Jr.: The diagnosis of interstitial cystitis revisited: lessons learned from the National Institutes of Health Interstitial CystitisDatabase study. J Urol. 1999; 161: 553-7.

Correspondence address:

Marcos Lucon, MD Division of Urology, University of Sao Paulo Medical School Rua Sararé, 211

Sao Paulo, SP, 05452-010, Brazil Fax: +55 11 3251-4276 E-mail: mlucon@uol.com.br 